\title{
O ideário automotivo e a sua repercussão sócio-espacial nas cidades: 0 exemplo do Rio de Janeiro
}

The automotive ideal and its social and spatial repercussion in cities: the example of Rio de Janeiro

El ideario automotriz y su repercusión socio-espacial en las ciudades: el ejemplo del Rio de Janeiro 


\section{RESUMO}

Em meados do século XX, diante da incorporação dos automóveis como novos elementos da via pública, temos a imposição de uma mudança significativa na gestão do espaço público. Essa forma de locomoção, tratada como possibilidade de mobilidade intra e interurbana, é responsável ,em discurso, pela possibilidade de percorrer maiores distâncias, mas na prática, por configurar uma nova dinâmica para os núcleos urbanos, e um novo processo de expansão das cidades. Usando o Rio de Janeiro como estudo de caso, o artigo cria um panorama das práticas de mobilidade na cidade no século XX, ao olhar as repercussões sobre a sua infraestrutura e práticas sociais, recorrendo a características do seu processo de expansão e da reconfiguração sócio-espacial do espaço urbano. Objetiva-se relacionar mobilidade, infraestrutura urbana e práticas sociais em um contexto no qual se consiga entender como as formas de locomoção e as estruturas viárias moldaram e moldam o espaço público refletindo na apropriação da cidade. Considerando uma interferência mútua entre mobilidade e layout urbano, a pesquisa engloba variadas escalas de abordagem, analisando as consequências dessa interação de três formas distintas: considerando o processo de expansão da cidade decorrente de um iminente incentivo ao uso do automóvel e a sua consequente redistribuição sócio espacial; observando espacialmente as mudanças de configuração de traçado e de vias somada a reestruturação do espaço público para receber essa eminente demanda; e por fim, elencando consequências dessas mudanças sobre outras formas de mobilidade e sobre a apropriação desses transformados espaços públicos pelos cidadãos.

PALAVRAS-CHAVE: Mobilidade Urbana; Práticas sociais; Infraestrutura Urbana.

\section{ABSTRACT}

From the 50's, against the need to accommodate cars as new elements of the public infrastructure, we have the imposition of a significant change in the management of public spaces. This form of locomotion, treated as a new possibility of urban mobility, is responsible, in speech, for the possibility to cover longer distances, but in practice, to set up a new urban dynamic to the existing urban core, and also a new process of expanding cities. Using Rio de Janeiro as a case study, the article seeks to create an overview of mobility practicies in the 20th century, with a look at the impact on its infrastructure and also on its social practices, using the features of its expansion process and socio-spatial reconfiguration of the urban space. The objective is related with the connection between mobility, urban infrastructure and social practices in a context in which it is possible to understand how the types of locomotion, and also their road structures, shaped and shape the public space, reflecting on the appropriation of the city in general. Given this perspective, and considering the mutual interference between mobility and urban layout, the search includes several scales of study, analyzing the consequences of this interaction in three different levels: first, considering the process of city's expansion, based on incentives to the car use in the last 70 years, and its consequent social redistribution in the urban space; in a second part, observing the changes on tracks and routes configuration, added to the restructuring of public space to receive this eminent demand; and finally, listing the consequences of these changes on other forms of mobility and the appropriation of these transformed public spaces by citizens.

KEY-WORDS: Urban mobility. Urban infrastructure. Social practices.

\section{RESUMEN}

A mediados del siglo XX, ante la incorporación de los automóviles como nuevos elementos de la vía pública, tenemos la imposición de un cambio significativo en la gestión del espacio público. Esta forma de locomoción, tratada como posibilidad de movilidad intra e interurbana, es responsable, en discurso, por la posibilidad de recorrer mayores distancias, pero en la práctica, por configurar una nueva dinámica para los núcleos urbanos, y un nuevo proceso de expansión de las ciudades. Con el Rio de Janeiro como estudio de caso, el artículo crea un panorama de las prácticas de movilidad en la ciudad en el siglo XX, al mirar las repercusiones sobre su infraestructura y prácticas sociales, recurriendo a las características de su proceso de expansión y reconfiguración socio-espacial del espacio urbano. Se pretende relacionar movilidad, infraestructura urbana y prácticas sociales en un contexto en el que se pueda entender cómo las formas de locomoción y las estructuras viales moldearon y moldean el espacio público reflejando en la apropiación de la ciudad. La investigación abarca variadas escalas de enfoque, analizando las consecuencias de esta interacción de tres formas distintas: considerando el proceso de expansión de la ciudad resultante de un inminente incentivo al uso del automóvil y su consiguiente redistribución socio espacial; observando espacialmente los cambios de configuración de trazado y de vías sumada a la reestructuración del espacio público para recibir esa eminente demanda; $y$, por último, en las consecuencias de estos cambios sobre otras formas de movilidad y sobre la apropiación de estos transformados espacios públicos por los ciudadanos. 


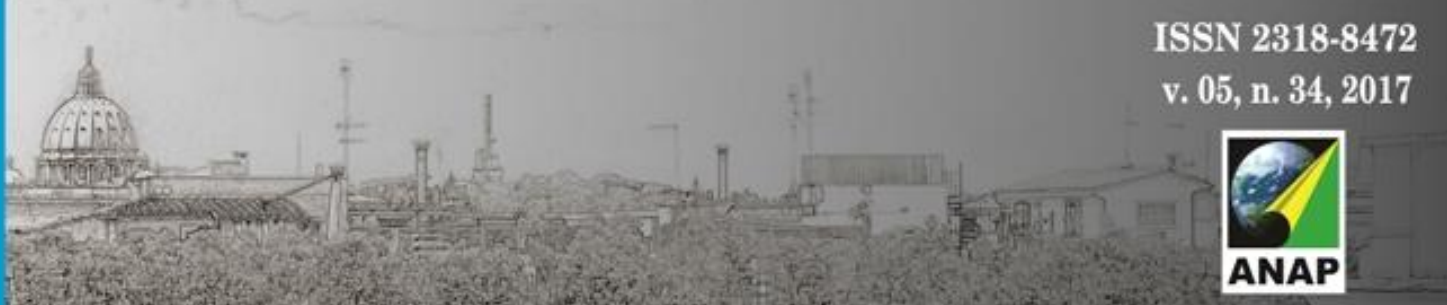

Gerenciamento de Cidades

National dournal of Citiux Manabement

PALABRAS CLAVE: Movilidad Urbana; Prácticas sociales; Infraestructura Urbana. 


\section{1 - INTRODUÇÃO}

A partir da década de 50, diante da necessidade de acomodar os automóveis como novos elementos da via pública, temos a imposição de uma mudança significativa na forma de gestão do espaço público. Essa forma de locomoção, tratada como nova possibilidade de mobilidade intra e interurbana, é responsável em discurso pela possibilidade de percorrer maiores distâncias, e na prática, por configurar uma nova dinâmica urbana para o existente núcleo urbano, e também um novo processo de expansão das cidades. Salingros (2006) explica que o modelo de urbanização dispersa, difundido a partir do séc $X X$, foi uma das consequências do incentivo ao uso dos automóveis nas cidades uma vez que suas vias se apresentavam como um dos elementos principais de conformação do espaço urbano.

Essa mudança de padrão morfológico cria um cenário onde as mudanças em características de densidade, diversidade e desenho urbano, afetam diretamente os padrões de deslocamento da população, que passa a estar atrelada a uma infraestrutura urbana (estrutura viária, quadras, lotes e edificações) reestruturada para atender essa recente demanda automobilística. Temos um quadro de interferência mútua entre essa nova possibilidade de mobilidade e o layout urbano, muito bem definido por Leivas (2013) quando se utiliza de uma citação de Wiel que expõe um sistema interativo entre as edificações e a mobilidade:

\footnotetext{
Viagens resultam do layout urbano(...). O oposto também é verdadeiro, que o layout urbano resulta das condições de mobilidade(...). Nós estamos em um sistema interativo onde o que é mais permanente - os prédios-e o que é mais efêmero- a mobilidade- moldam permanentemente um ao outro, seguindo um processo evolutivo que é overall (tudo interage com tudo) e contínuo (sem um escopo de duração). Essa reciprocidade(...) forma o conceito de cidade. (M. WIEL, Ville et Automobile, 2001)
}

As consequências dessa interação e interferência mútua e contínua podem, inicialmente, ser analisadas de três formas a serem abordadas no presente artigo: primeiro, analisando o processo de expansão da cidade decorrente desse incentivo ao automóvel e a sua consequente redistribuição sócio espacial; em segunda vertente, observando espacialmente as mudanças de configuração de traçado e de vias somada a reestruturação do espaço público para receber essa eminente demanda; e por fim, elencando as consequências dessas mudanças sobre as outras formas de mobilidade e sobre a apropriação desses transformados espaços públicos pelos cidadãos. Wilhein (2013) fala de infraestruturas físicas e sistemas de vida, avaliando se as primeiras dão suporte adequado às segundas.

A associação entre sistemas de vida e infraestruturas físicas nos revelará sua adequação ou a inadequação: suportará a estrutura física o sistema de vida que nele se apoia? Ou, como é mais comum, a infra é deficiente para suportar o sistema de vida? Também poderá ocorrer que exista infra física 
sem que haja sistema de vida algum a nela buscar suporte, embora por vezes o órgão acabe criando uma função. (WILHEIN, 2013)

Deve ser observado que o planejamento e dimensionamento da infraestrutura física das cidades para responder primeiramente a um modelo de mobilidade em função de carros, repercutem na morfologia e na malha urbana das cidades apresentando e moldando características urbanas em distintas escalas e com consequências principalmente nas formas de apropriação e vivência de seus espaços públicos. Essas formas de apropriação são os sistemas de vida citados por Wilhein, onde se encaixam a presença de pessoas nas ruas, grupos em interação, trocas microeconômicas, e também as locomoções por meios não motorizados.

Se tratarmos de eixos urbanos de conexão, a relevância da mobilidade e de suas repercussões espaciais torna-se cada vez mais evidente na prática e expressão da vida coletiva, estimulando ou limitando possíveis trocas sociais e também dos cidadãos com o espaço público. $\mathrm{O}$ valor estratégico desses eixos está no que Choay afirma entender como urbanidade - o ajuste recíproco entre uma forma de tecido urbano e uma forma de convivialidade. A hostilidade de muitos ambientes urbanos aponta, hoje, para a emergência de um planejamento urbano pautado pela (re)conquista do convívio, pela coexistência com o diferente e o resgate dos valores de urbanidade. Já no final do século, com a busca de alternativas ao uso excessivo do veículo automóvel por razões variadas, sejam elas ambientais, de saúde, de sustentabilidade, econômica ou preservação da qualidade do espaço público (IShaque e Noland, 2008), além da qualidade da mobilidade nas cidades, voltamos a observação de uma vertente de pensamento do espaço viário em prol de pedestres e novas formas de locomoção, e em suas acomodações em um espaço público já moldado, mesmo que em somente 50 anos, para os automóveis.

Com o Rio de Janeiro como estudo de caso, o artigo busca criar um panorama de práticas de mobilidade, e suas repercussões sobre a infraestrutura e práticas sociais, recorrendo a características do processo de expansão e da reconfiguração sócio-espacial do espaço urbano.

\section{2- OBJETIVOS}

O artigo é fruto do trabalho de dissertação "Bicicletas, pedestres e cidades: um estudo sobre mobilidade urbana", da Universidade Federal Fluminense, e busca demonstrar os seus resultados que tangem as consequências das opções pela mobilidade por meio de automóveis, adotadas em grande parte do planejamento urbano da segunda metade do século XX.

Objetiva-se mostrar como o processo de expansão da cidade do Rio de Janeiro teve, na mobilidade, uma de suas ferramentas de organização sócio espacial, mas sendo esta ao mesmo tempo, uma grande e atual alternativa para novas soluções e melhorias da qualidade urbana da cidade. É necessário nessa análise, entender os fluxos da cidade, com a devida atenção a suas origens e destinos, além dos meios de locomoção utilizados para tal. Cabe também, perceber se essa infraestrutura de transportes responde as demandas da cidade e aos sistemas de vida nela 
presentes como já destacado. Aqui se associa outra vertente do trabalho, em uma redução de escala, com a tentativa de trazer consequências e alterações das ações de mobilidade realizadas na cidade sobre diversos espaços públicos, elencando exemplos de recortes urbanos, falta de relação com entorno entre outros aspectos por elas ocasionados.

O objetivo geral é relacionar mobilidade, infraestrutura urbana e práticas sociais em um contexto no qual se consiga entender como as formas de locomoção e as suas estruturas viárias moldaram e moldam o espaço público refletindo na apropriação da cidade de forma geral.

\section{3- METODOLOGIA/ MÉTOdOS DE ANÁLISE}

O caminho metodológico adotado nos remete a diversas correntes de estudo que se relacionam aos preceitos no trabalho já citados, mostrando conexões entre conceitos, características urbanas e também ferramentas de pesquisa (cartografia, gráficos, entrevistas) aplicadas na cidade do Rio de Janeiro como objeto de estudo.

A primeira corrente metodológica trata de uma análise do crescimento urbano da cidade, principalmente a partir da observação de sua mancha urbana. Falamos de uma escala de abordagem da densidade, que em ideal preza pela consolidação de uma cidade compacta em termos de área, diferente de um processo de dispersão urbana resultado da periferização e suburbanização adotados no século XX. Os estudos se baseiam nos trabalhos de Panerai (2008) que relacionam concentração da mancha urbana e raios por ele considerados estruturantes dentro da formação de uma cidade. Dentre os resultados, se vê uma organização funcional da cidade de Xangai facilitada pela inserção de praticamente toda sua área urbana dentro de um raio de 12 quilômetros.

Essa compactação da mancha urbana da cidade repercute diretamente na diminuição de distâncias facilitando na construção de mais simples e eficientes redes de transporte público e de informações, impulsionando a mobilidade por todo território inclusive ao nível do pedestre que também vê a distância dos serviços, e trabalho, por exemplo, diminuídas. Falamos de um dos aspectos necessários para o estímulo da vitalidade urbana, destacado por Netto (2012) como um conjunto de condições encontradas em espaços em que há intensa presença de pessoas nas ruas, grupos em interação e trocas microeconômicas.

Para entender essa relação de crescimento $X$ densidade, duas outras abordagens metodológicas se fazem necessárias: primeiro um breve entendimento histórico da expansão da cidade de onde vamos entender também o seu processo de ordenamento sócio-espacial e como a infraestrutura de mobilidade se adequou e respondeu a essa nova perspectiva; posteriormente, cabe decifrar, morfologicamente, exemplos de malhas urbanas e suas conexões a esse contexto, vendo configurações de traçado com seus índices de conectividade e integração, além da sua associação ao número de pedestres circulando.

Em próxima análise, absorvendo já as informações quanto à forma de crescimento da cidade e sua configuração espacial, serão observados como as malhas urbanas foram se adequando a 
esse crescimento e também a essa priorização do transporte automotivo durante o século XX. Essa análise morfológica permite depois, em escala reduzida, perceber as consequências locais da abertura dessas novas grandes vias que recortam muitos dos bairros da cidade, trazendo mudanças bruscas de traçado e também na interação de seus usuários com o espaço. Serão dados exemplo dos bairros do Centro, Cidade Nova/Estácio, Flamengo e Penha para elucidar algumas dessas consequências.

Os dados recolhidos através de questionários e estudos de sintaxe urbana desses bairros se somam nesse entendimento da interação de usuários e espaço público, e serão apresentados em resumo, com intuito de mostrar a sequência metodológica da pesquisa. Todo esse material está disponibilizado na dissertação a qual o artigo se associa. Esses estudos, somados as pesquisas de Origem e Destino disponibilizadas pelo IPEA, remeteram ao entendimento dos fluxos locais e também para outros pontos da cidade, desde os motivos pelos quais são realizados, até os meios de transportes utilizados. Levam também ao entendimento da percepção dos usuários quanto aos aspectos de mobilidade e acessibilidade dos bairros em que foram entrevistados, assim como de infraestrutura.

\section{4-RESULTADOS}

\section{1- PROCESSO DE EXPANSÃO, ANÁLISE VIÁRIA E DE MEIOS DE TRANSPORTES}

Considerando o histórico de formação do Rio de Janeiro como primeira análise, percebem-se tendências de alargamento estrutural e de crescimento da sua mancha urbana já a partir do final do século XIX. Processos de adensamento e formação de novos bairros acompanharam a sua evolução urbana, orientada pelo desenvolvimento dos meios de transporte e vias, sendo uma questionável facilidade de mobilidade, um dos grandes impulsores desse crescimento. A cidade cresce, em direção a Catete e Glória, em função das possibilidades geradas por esse poder de mobilidade, inicialmente baseado na locomoção por bondes.

Identificamos também, associado a esse processo, o lançamento dos elementos para a separação gradual dos usos e classes sociais, que antes não ocorria no centro da cidade, área correspondente ao seu núcleo de formação, e por muito tempo, a totalidade de sua mancha urbana. Durante esse processo, percebemos a força de alguns dos elementos citados por Le Febvre (1991) como essenciais para o desenvolvimento urbano e também industrial nessa fase histórica: o acesso aos meios de transporte e a proximidade de uma reserva de mão de obra concentrada em uma região da cidade, que no caso do Rio seriam os arredores de onde se encontra o campo de Santana e o então crescente bairro de São Cristóvão.

Saímos de uma cidade com mancha urbana e conjunto de atividades concentrados no centro, para um processo de expansão para sul onde classes nobres da cidade começam a se estabelecer, e para norte onde se concentram as classes menos favorecidas. A cidade do Rio de Janeiro começa a se desenvolver seguindo a lógica de localização de atividades, com uma centralidade que concentrava comércio e serviços, e uma região residencial que se estabelecia 


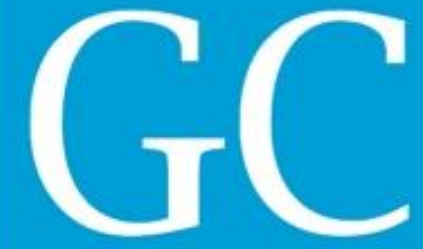

Revista Nacional de

nos seus arredores. Essa forma de expansão se dá continuamente até o século XX com o a concretização do desenvolvimento do subcentro de Copacabana e uma ocupação rarefeita em termos densidade da Zona Norte. Anteriormente, até meados do século XIX, a setorização de usos e também de classes sociais era praticamente inexistente, se concentrando em maioria na área central da cidade, sendo um mesmo edifício, lugar de residência, trabalho e comércio.

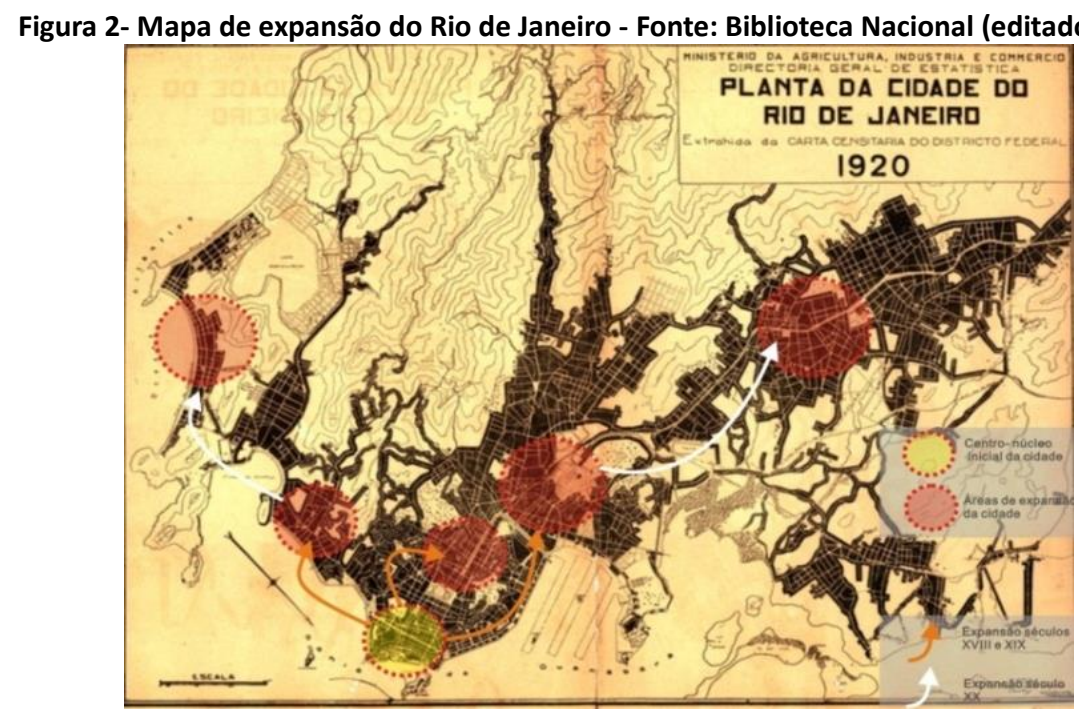

Fonte: Biblioteca Nacional (editado), 2014

As características de traçado começam a responder a essa expansão, e esse período é marcado pela abertura ou ampliação de ruas na formação de eixos estruturais. É datado do final dos anos 30 o início das obras da Avenida Presidente Vargas, responsável pela demolição de um número aproximado de 500 prédios, e pela total desconfiguração de um traçado urbano antes pensado em menor escala para atender demandas de uma locomoção a pé e para apropriação da cidade por esses transeuntes. Os reflexos desse recorte urbano, melhor detalhados posteriormente, são observados até hoje, seja na configuração arquitetônica das suas edificações lindeiras, com "plinths" pouco ativos, ou na pequena circulação de pedestres em um grande trecho de sua extensão, consequência de uma via pensada com até 10 caixas de rolamento para automóveis e fora da escala humana de um espaço público, essencial a cidades.

Essa política automotiva e de abertura de grandes vias é, a partir desse momento, difundida pela cidade, seja na "remodelação" e criação de bairros, com vias arteriais secundárias que alavancam conexões de grandes distâncias, pulverizando apropriações e ligações locais, ou na principal política de mobilidade adotada durante quase todo o século $\mathrm{XX}$, de planejamento global da cidade, baseado em um processo de expansão através da abertura de vias expressas e arteriais principais.

As consequências dessa política surgem em diversas esferas do pensamento urbano. Os exemplos, como mostrados no mapa a seguir, são de grandes arteriais que, somadas ao relevo acentuado da cidade, moldam os traçados urbanos dos bairros, criando descontinuidades e 


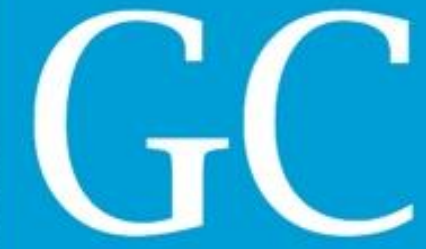

Revista Nacional de

rupturas do espaço urbano (fotos da Linha Amarela e Vermelha), além da criação de arquiteturas que respondam a essa velocidade de locomoção (Gehl (2014) e a arquitetura a $60 \mathrm{~km} / \mathrm{h}$ ), com baixo nível de detalhamento de fachada, poucas aberturas para o espaço público, grandes dimensões e desconexão com a escala do pedestre (foto Autoestrada Lagoa-Barra). Soma-se ainda a priorização de um modo de transporte ineficiente, com a saturação de suas vias (foto da Avenida Brasil) e que é acompanhado por um processo de expansão que desconsidera a eficácia das pequenas distâncias como fator de crucial importância para a formação de redes: bairros como Santa Cruz e Campo Grande, com entorno de 150 mil habitantes cada um, estão localizados a uma média de $50 \mathrm{~km}$ do centro, que nos horários de pico são percorridos em mais de 2 horas por seus moradores, segundo entrevistas da pesquisa.

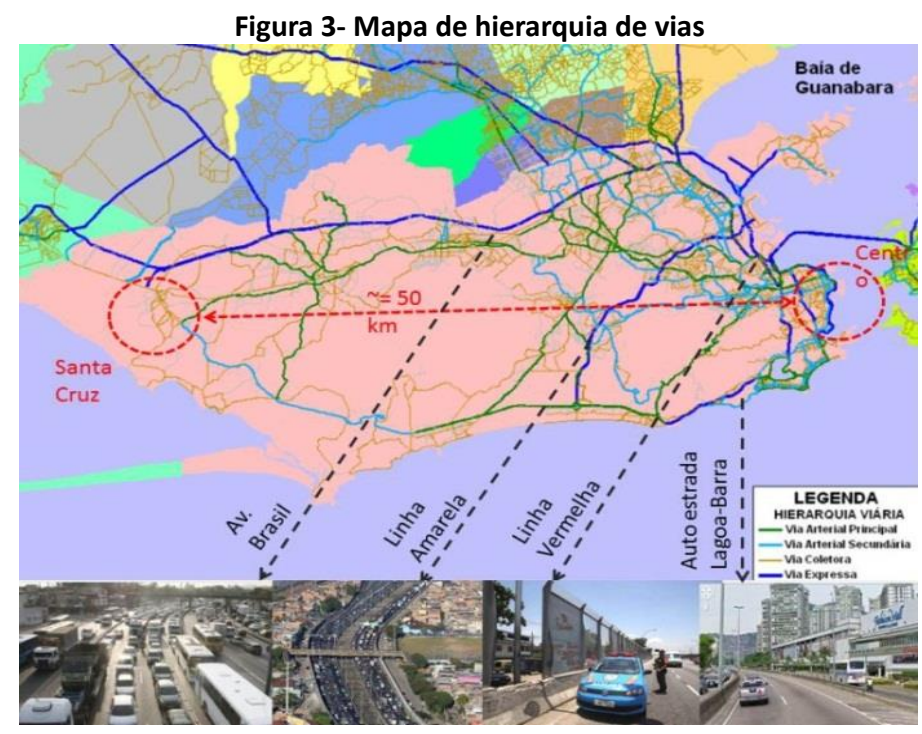

Fonte: Biblioteca Nacional (editado), 2016

Braga (2008) destaca que um dos problemas mais incidentes diz respeito à confusão entre acessibilidade e mobilidade, ao se interpretar a primeira como atributo exclusivo do sistema de transporte sem considerar o grau de atração das oportunidades oferecidas nas zonas de destino. A acessibilidade associa-se à capacidade de alcançar um determinado lugar, enquanto a mobilidade relaciona-se com a possível facilidade desse deslocamento.

Neste último quesito, que o planejamento urbano da cidade, pensado nesses grandes eixos de circulação de carros pecou, possibilitando a acessibilidade aos pontos centrais da cidade, mas com uma demanda não suprida por essa infraestrutura. Segundo pesquisa da Firjan (2015), no Rio de Janeiro, 2,8 milhões de pessoas perdem 2 horas e 21 minutos em média, para realizar o trajeto casa-trabalho duas vezes ao dia. Essa dificuldade de acesso tem algumas das causas já citadas aqui: os incentivos ao transporte individual motorizado e o não planejamento da expansão da cidade que, de forma horizontal, criou uma estrutura urbana difícil de ser atendida por completo pelas diversas redes que se fazem necessárias (transportes, esgoto, empregos 
entre outras). Recentemente a expansão do tecido urbano continua para a zona oeste com a consolidação da Barra da Tijuca como uma nova centralidade que apesar da sua importância econômica, assim como concentradora de serviços, prioriza uma ocupação de baixa densidade e rarefeita (entorno de $50 \mathrm{hab} / \mathrm{m} 2$ ), voltada para a circulação por automóveis em detrimento da circulação a pé e por transportes de massa.

Em termos globais, estudada a conectividade de toda a cidade, a integração se torna prejudicada por essa contínua dispersão da mancha urbana associada principalmente ao difícil relevo, acentuando assim o grau de conectividade das vias arteriais em relação as demais, e reforçando a dependência das mesmas e os consequentes engarrafamentos em suas extensões. Usando comparativo da dissertação, Xangai, apresenta um cenário mais interessante do que o Rio, considerada a concentração de sua malha viária. Têm-se duas formações distintas de cidade: 0 Rio moldado por seu relevo e por vias expressas que estimulam uma expansão do território periférica, com adensamento de áreas distantes da zona central, enquanto Xangai se volta ao seu centro com uma forma de expansão compacta dentro de um raio limitado. Temos dois fatores fundamentais nessa conformação: a posição do centro da cidade e a diferença de geografia física. Em Xangai a coincidência entre o centro da cidade e o centro geográfico da mancha urbana, permite uma expansão radial facilitando conexões, dispersão de fluxos, execuções de infraestrutura e a densificação de áreas.

Figura 4- Rio de Janeiro e Xangai- processos de expansão de infra estrutura - expansão linear X expansão radial

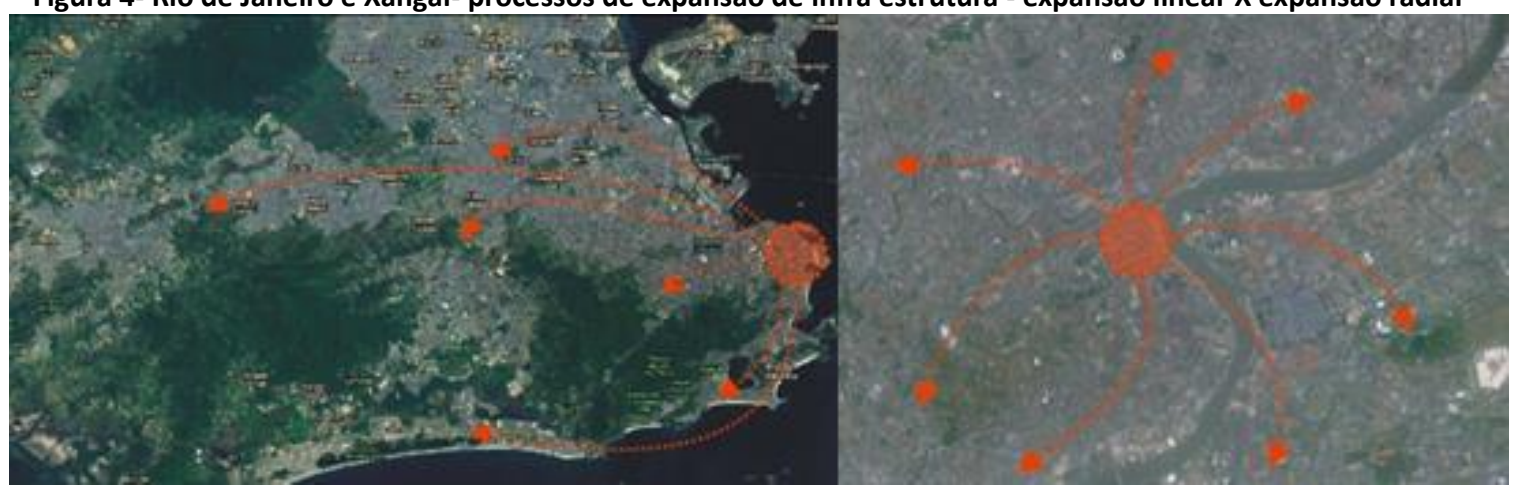

Fonte: DADOS DE PESQUISA, 2014.

O Rio por sua vez tem seu centro econômico na margem leste de sua mancha tendo toda uma confluência de fluxos para um ponto não central. As resultantes desse fator são limitações em termos de número de vias que chegam à área central além da perda de conexões entre bairros que se dariam no centro. Essa diferença ainda se acentua se levarmos em consideração o território plano de Xangai relacionado ao relevo do Rio que acentua o crescimento da mancha urbana visto que a mesma é modelada por esses aclives que se encontram no meio da cidade carioca. A eles se somam o mar, a floresta da Tijuca o Parque Estadual da Pedra Branca e o Parque de Marapendi, além das lagoas de Jacarepaguá e Tijuca- todos condicionantes físicos do crescimento da cidade. 
Em importante estudo sobre a estrutura urbana, Panerai (2008) desenvolve a noção de raios estruturantes dentro da formação da cidade: o primeiro com 12 quilômetros como aquele ideal para que a sua mancha urbana estivesse inserida, e o segundo, de 18 quilômetros, como o raio limite para que se obtivesse uma eficiência de transporte e de conexões dentro da cidade. No centro desses raios estaria a sua região central para onde se convergem grande parte dos fluxos da cidade.

Ao contrário de Xangai com raio de 20 quilômetros, o Rio de Janeiro se insere em um raio de 50 km (distância topológica), tendo Santa Cruz, bairro com população superior a 150 mil pessoas, a essa distância da área central. A comparação se torna ainda mais discrepante quando analisada as populações das duas cidades que segundo ONU gira entorno de 17,8 milhões em Xangai enquanto no Rıo não chega a metade; entorno de 6,32 milhões. Com essas relações entre áreas e populações, chegamos a uma densidade de 6845 hab./km2 em e 5015 hab./km2 no Rıo de Janeiro desconsiderada a área da floresta da tijuca, que aumentaria a discrepância.

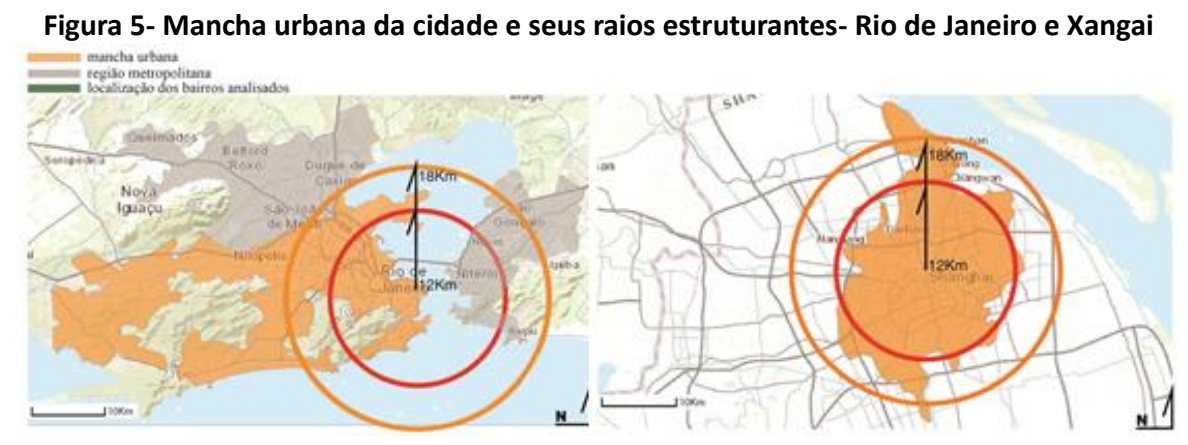

Fonte: DADOS DE PESQUISA

Em termos de mobilidade, as repercussões dessa expansão horizontal aliada a essa baixa densidade são enormes tendo, com esse distanciamento de bairros, um transporte de massa que tende a ser desenhado em estrutura linear. Mesmo que ele chegue a determinado perímetro urbano, este não tem a totalidade de sua área servida por esse transporte devido à falta de conexões propiciadas por uma rede em malha.

Associa-se aqui o transporte de massa ao conceito de caminhabilidade para analisar esse atendimento da rede: consideradas as estações como os destinos e os pontos de partida de pedestres dentro de seu bairro (o transporte de massa os levaria a outra área da cidade onde os mesmos também optariam por caminhar), temos um raio de alcance de cada estação de $1 \mathrm{~km}$, correspondente a 10 minutos de caminhada. Em um cenário ideal duas estações próximas deveriam estar distantes uma das outras em uma média de $1 \mathrm{~km}$ para que os pedestres pudessem fazer caminhos que necessariamente não sejam sempre de um ponto a mesma estação de transporte, e depois o caminho inverso. Trata-se aqui de uma gama de possibilidades de rotas e escolhas de trajetórias que proporcionam o que Netto (2012) define como vitalidade 
- um "conjunto de condições encontradas em espaços em que há intensa presença de pessoas nas ruas, grupos em interação e trocas microeconômicas".

Defende-se que quanto maior o grau de conexão da rede de transportes de massa de uma cidade, maior o número de pessoas que por ela circulam a pé e de bicicleta. Em grandes metrópoles, a associação dos transportes não motorizados ao transporte de massa é elemento fundamental ao tratarmos de mobilidade. Os vínculos entre territórios e atividades tratados por Barreto e Gislon (2013) seriam exatamente o transporte de massa e a vizinhança caminhável abordada por Rattan (2012) estaria relacionada a essa possibilidade de andar até distintos pontos nodais de transporte onde, no caminho, uma gama de atividades e usos acontecesse.

O mapa abaixo mostra a malha de transporte de massa (metrô e trem) do Rio de Janeiro associando a esses transportes as distâncias caminháveis a partir de cada uma das estações: um primeiro raio de 500 metros, considerado ideal, e um segundo de $1 \mathrm{~km}$ representando o alcance de cada estação levando em conta uma caminhada de 10 minutos.

Figura 6- Distâncias caminháveis a partir das estações de transporte de massa- em cinza áreas não tendidas da

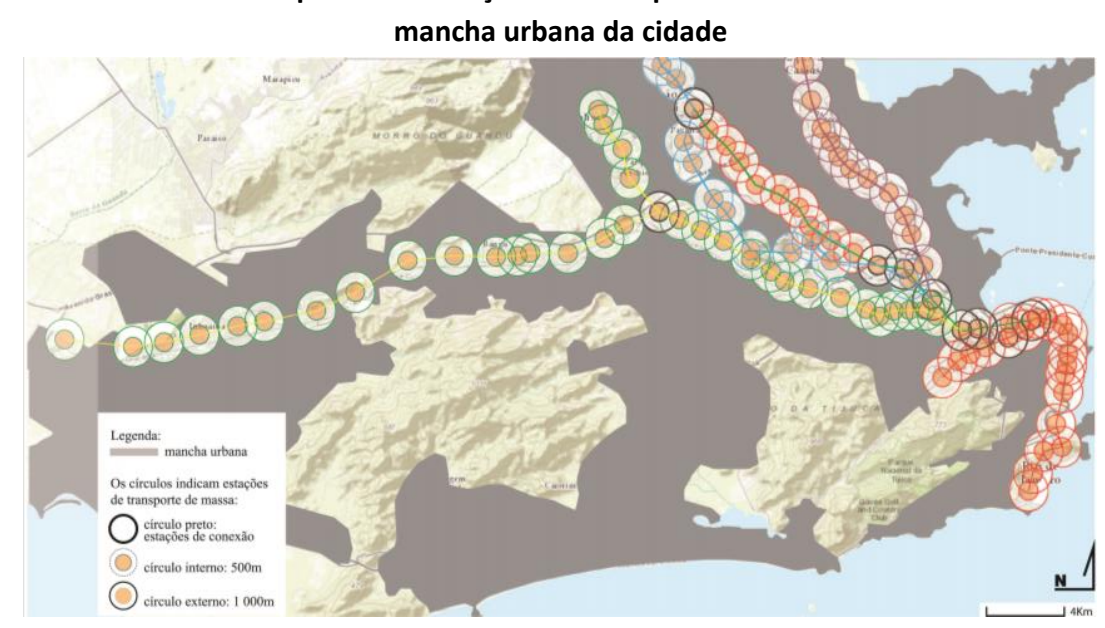

Fonte: DADOS DE PESQUISA

Percebe-se uma realidade, onde a cidade sofre com uma precariedade em termos de número de linhas e principalmente pela expansão linear da rede que faz com que grandes áreas não sejam acessíveis a pé, distantes mais de $1 \mathrm{~km}$ de uma estação. A zona norte da cidade é exemplo dessa falta de integração entre as linhas de transporte de massa e o caminhar até essas estações - mesmo com 5 linhas de metrô ou trem que cheguem a área, elas se encontram desconectadas ficando algumas áreas fora do alcance das estações.

A consequência dessa carência de transporte de massa é a opção por outras formas de transporte, seja ele coletivo ou individual. O primeiro, com os ônibus tem seu problema no fato deste ser um transporte que segue uma lógica de rotas e paradas distintas a dos trens e metrôs: busca ao invés de conexões diretas, o atendimento de uma área mais ampla com um maior número de paradas o tempo de locomoção maior. Relacionado à caminhabilidade, os pontos 
mais próximos diminuem os tempos de caminhada diminuindo também possibilidades de interação social e com o espaço - estes criados pela presença de pessoas na rua. Este é problema compartilhado com o transporte individual motorizado que pulveriza a relação do usuário com o espaço público, visto que ele o leva da origem ao destino diretamente, sem o caminhar pelas ruas e o estar em um espaço público. Wilhein (2013) ressalta exatamente o efeito, ao circular na condição de pedestre ou de ciclista, a fim de ter o tempo e a calma necessários à percepção. Voltando a análise do mapa de distâncias caminháveis a partir das estações, vemos além das questões discrepantes de crescimento linear (Rio) $X$ crescimento radial ideal uma terceira importante questão: a existência de uma linha circular que conecte as demais linhas de forma a facilitar a locomoção para outros pontos que não seja a área central. Analisando o mapa do Rio de Janeiro, e considerando Santa Cruz como estação mais distante, a troca mais frequente de estação para outra linha seria na Central do Brasil, distante 35 estações. 0 tempo gasto em paradas até o ponto de conexão com outra linha é de em média 35 minutos considerando uma média de 1 minuto por estação. Um transporte que seria caracterizado pela eficiência em questões de tempo acaba por se tornar lento visto esse excessivo número de paradas. A consequência desse distanciamento de conexões é a opção por outra forma de transporte, já que o tempo despendido na locomoção até a estação (caminhar), somado ao tempo em paradas e conexões torna o transporte de massa ineficiente. Considerados, os pontos de Wilhein, podemos somar como motivo dessa escolha, o conforto dos trens visto que uma linha tão extensa repercute em um maior número de pessoas que a usa podendo representar vagões superlotados.

É importante constatar, que junto a esse não atendimento do transporte de massa, e também a esse processo de expansão horizontal, está associada a reestruturação sócio-espacial da cidade, que já abordada na contextualização histórica, mostra que essa expansão pra norte, ocorreu com o assentamento das populações mais pobres da cidade. Considerada a maior carência dessa infra-estrutura exatamente nessa área, podem ser analisados aspectos de segregação territorial nesse processo de expansão, os quais seriam impossíveis de também serem detalhados no artigo, mas quem têm na mobilidade uma de suas grandes ferramentas. Voltando ao mapa e considerando as áreas centrais, percebemos, no comparativo da dissertação, em Xangai quase que a totalidade de seu centro inserida dentro de um dos raios de 500 metros a partir das estações (associação entre o transporte de massa e o caminhar). Já no Rio, grandes áreas centrais se encontram dentro do raio de atendimento de um quilômetro podendo representar a opção por outro transporte coletivo após o uso do transporte de massa. Essa opção ainda se torna mais viável visto o incentivo do governo para essa integração, com a implantação do sistema de bilhete único, uma medida paliativa ao incompleto alcance das linhas de metrô e trem. Essa medida elimina a conexão entre o caminhar e o transporte de massa aqui comentada. Consideradas as proximidades da área central, fica mais evidente esse alcance do transporte de massa de Xangai em relação ao Rio visto quem em uma distância de 6 quilômetros de La Bund e Pudong (região central), ainda temos áreas completamente inseridas nos raios de 
1 quilômetro e quase que em totalidade dentro dos raios de 500 metros. Enquanto isso no Rio, áreas como o bairro do Caju, distante a menos de dois quilômetros da Central do Brasil (estação nodal da rede), não se encontram nem inseridas no raio de 1 quilômetro de alguma estação.

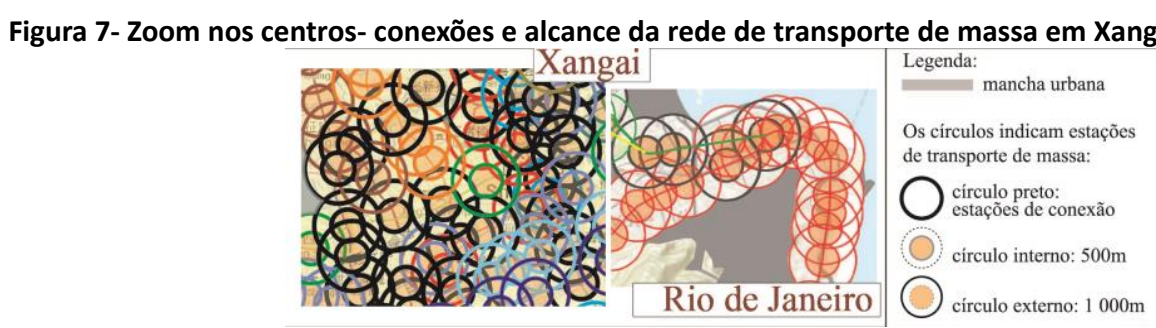

Fonte: DADOS DE PESQUISA

\section{2- ANÁLISE BAIRRO A BAIRRO E PERCEPÇÕES LOCAIS}

As distâncias caminháveis a partir de uma estação podem também ser observadas em menor escala, sendo o primeiro elemento a ser analisado para entender as consequências locais (escala de bairro e rua) dessa opção automobilística de mobilidade e expansão adotada na cidade. Falamos aqui que, decorrente desse processo, a não priorização do transporte de massa pode mudar dinâmicas e circulações dentro de um bairro.

Analisado o bairro da Penha, vemos a estação de trem como importante elemento da vida urbana, tendo, na contagem de pedestres, nos portões próximos a elas, a maior circulação de pessoas dentro do bairro.

Nesse quesito vemos a centralidade da estação de trem como ponto chave da urbanização da área, tendo nos portões localizados em seus acessos, fluxo que chega a ser 4 vezes maior do que em outros pontos do bairro, criando uma estrutura interessante de usos e construções ao seu redor. Essa estrutura se modifica ao distanciar da estação entre outros aspectos por essa análise de distâncias caminháveis, visto o não atendimento completo de toda a área.

Ao contrário desse centro de bairro, a Avenida Brasil, via expressa que faz a ligação com o centro da cidade, assim como em muitos dos bairros da zona norte, tem a estrutura local "de costas" para a via, sendo um recorte da malha urbana de bairro, com uso em suas margens majoritariamente de grandes galpões, e atividades voltadas para carros e não pedestres. Ainda assim, devido ao não atendimento da totalidade da área pelo transporte de massa, temos em horários de pico, um fluxo de pessoas em direção a avenida, para recorrer ao transportes público por ônibus. Ainda que esse fluxo exista, a estrutura urbana criada por esses grandes eixos, não é nada convidativa aos pedestres, que se põem em situação de conflito com carros, e insegurança. Ítens observados nas entrevistas, relacionam as menores notas exatamente a esses dois aspectos, tendo em uma escala de 0 a 5, a segurança com nota mais baixa, 1,36 (de 0 a 5 ) seguidas de pelo nível de barulho e fumaça de carros $(1,94)$ e número de carros na rua/ relação entre eles e os pedestres (2,06 ). Com esses aspectos, muitos optam pelo carro como meio de 
transporte, já que a estrutura viária a eles oferecida estimula seu uso, tendo entorno de $40 \%$ dos entrevistados indo ao trabalho ou a compras desta forma.

Falamos de um ciclo em que, o não desenvolvimento do transporte de massa,em prol de um modelo automobilístico de desenvolvimento, nos leva a áreas de um bairro, que não atendidas por trens e metrôs, têm sua estrutura pensada para os carros, gerando um ambiente hostil para pessoas caminharem e resultando na opção pelo transporte automotivo. Com essa escolha, mais espaços são pensados nessa escala pouco humana, acabando com relações de apropriação e vivência do epaço público. Esta apropriação, em muito é gerada pela opção transporte público/caminhar e pela dinâmica urbana a ela acoplada, de usos e propriedades físicas das edificações e dos espaços públicos.

Figura 8- As diferenças de escala e apropriação criadas por estruturas de mobilidade diferentes (Penha)

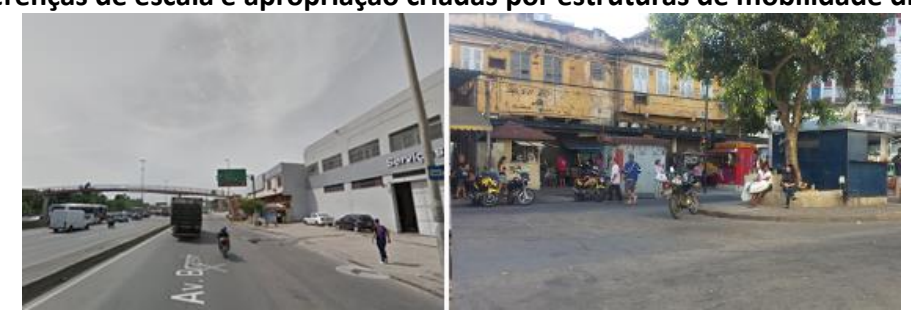

Fonte: GOOGLE STREET VIEW e DADOS DE PESQUISA

Temos nesses grandes eixos a percepção da falta de urbanidade em todos os métodos de análise utilizados, qualquer que seja o bairro abordado. É o caso da Cidade Nova, cortado pela Avenida Presidente Vargas citada anteriormente. Considerando o estudo das edificações que margeam a avenida, seus prédios, se relacionam de forma negativa com o espaço público, ausentes de uso comercial, e com grande parte de seu perímetro sem aberturas para a rua. Essa característica arquitetônica, junto a outras como fechamentos do lote, densidade construída e afastamentos, é consequência exatamente da escala de $60 \mathrm{~km} / \mathrm{h}$ citada por Gehl (2013). Temos um bairro pensado com uma estrutura de uso majoritariamente institucional e uma circulação intensa de carros, propiciando consequente, a falta de hospitalidade para pedestres e a quebra da relação público-privada. Recorremos novamente as notas de segurança nas entrevistas, de 1.82 (de 0 a 5) para o bairro, mostrando o total descontentamento com tal item. Associa-se aqui a insegurança, a um modelo urbano gerador de características arquitetônicas com baixa relação com o pedestre, percebidas em edifícios próximos aos portões onde foi constatada um menor número de transeuntes. No próprio bairro, temos o exemplo contrário, onde longe dos grandes eixos, percebemos áreas com uma tipologia contínua e com maior uso misto, apresentando maior fluxo de pedestres (portões próximos ao Estácio, caracterizado por tal tipologia). 
Figura 9- As diferenças de escala e arquitetura criadas por estruturas de mobilidade diferentes (Cidade Nova)

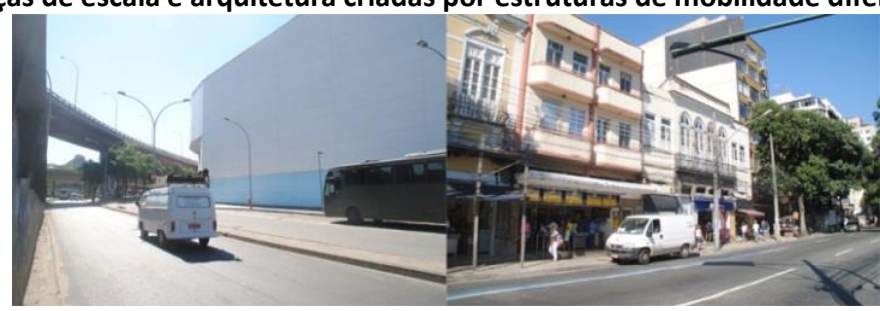

Fonte: DADOS DE PESQUISA

\section{5- CONCLUSÃO}

Os resultados nos outros dois bairros criam também, um panorama interessante pautado na relação entre a análise de atendimento do transporte de massa (distâncias caminháveis), as entrevistas (escolhas de transportes),e o estudo de morfologia das vias (relação carroXpedestres) e de edificações (usos). A contagem de pedestres mostra que em espaços públicos com grandes alterações devido a esse planejamento urbano em prol do carro, temos um menor fluxo de transeuntes. É constatada nessas vias, uma menor relação das edificações com o espaço público, se baseando na diversidade de usos e nas aberturas dos térreos.

O bairro do Flamengo mostra uma realidade interessante nesse aspecto, tendo suas principais vias, absorvido além do fluxo de carros, um grande número de pedestres circulando, o mesmo acontecendo nas suas ruas locais. As características urbanas que justificam essa apropriação são distintas e conversam com muitas das teorias expostas no artigo, entre elas o atendimento de toda a área por três estações de metrô (distância menor que dois quilômetros entre elas), escala de rua pensada em prol do pedestres com caixa de rua adequada e boa relação entre pedestres e carros, e usos mistos e fachadas ativas.

Em maior escala, o bairro também se encontra em conformidade com os parâmetros estabelecidos estando próximo das áreas centrais, com distâncias percorríveis a pé e que proporcionam um fácil atendimento de infraestrutura de mobilidade. As entrevistas confirmam essa estrutura ao constatar que somente $11 \%$ dos entrevistados utilizam o carro pra atividades corriqueiras ( ir ao trabalho, compras e lazer) e as notas relacionadas a conexão (facilidade de trocar de rota e caminho, acesso a pontos nodais de transporte, acesso a facilidades e equipamentos e acesso ao transporte público) giram entorno de 4,2 numa escala de 1 a 5 .

Ao contrário, na Penha, a 12 quilômetros do centro e já considerada um bairro periférico, essas notas ficam entorno de 3,3, já mostrando a discrepância no atendimento do transporte de massa e também a ineficácia desse modelo de expansão da cidade baseado nos transportes por carros e grandes eixos.

Temos assim, diante desse quase um século de incentivos ao carro, um cenário que no permite identificar implicâncias do planejamento do sistemas de transportes de um cidade em características urbanas das mais variadas, e ainda mais, possibilita criar novos parâmetros que incentivem a mobilidade por meios não motorizados e pelo transporte de massa, modificando 


\section{Revista Nacional de}

estruturas em escalas distintas, desde processo de adensamentos de centros a criação de vias locais em escala mais humana e que incentivem uso misto e plinths ativos.

\section{6- REFERÊNCIAS BIBLIOGRÁFICAS}

BARRETTO, Margarita; GISLON, Jacinta - O flâneur revisitado: processos de revitalização urbana e caminhabilidade. Revista Hospitalidade, V.X núm 1 - Junho 2013.

BRAGA, A (in) justiça social e a cidade: Notas sobre acesso e equidade no transporte público urbano. Dourados: Terra Livre, n31, p133-144, 2008.

CHOAY, Françoise. L’urbanisme, utopies et réalités: une anthologie. Paris: Seuil, 1965.

GEHL, Jan. Cidade para pessoas. 2ª ed.. São Paulo: Perspectiva, 2013.

ISHAQUE, M. ; NOLAND, R. Behavioural issues in pedestrian spped choice and street croosing behavior. Tranport Reviews: A transnational transdisciplinary Journal, n28, pag 61-85, 2008.

LEFEBVRE, Henry. O direito a cidade. 1ạ ed. São Paulo: Moraes, 1991.

LEIVAS, Gustavo. Forma urbana e padrões de deslocamento focados na bicicleta. Rio de Janeiro: Dout., UFRJ-- 2012.

NETTO, Vinícius; VARGAS, Júlio ;SABOYA, Renato. (Buscando) Os efeitos sociais da morfologia arquitetônica. Porto Alegre: Urbe. Revista Brasileira de Gestão Urbana, v. 4, n. 2, p. 261-282, jul./dez. 2012.

PANERAI, Philippe. Paris Métropole. Formes et Echelles du Grand Paris. Paris: Editions de la Vilette, 2008.

RATTAN, Arjun. Modeling Walkability. Australia, 2012.

SALINGROS, Nikos A. Compact City Replaces Sprawl. Rotterdam: Architecture, Urbanism, Technology. 2006.

WILHEIN, Jorge. “Mobilidade Urbana: um desafio paulistano”. São Paulo: Estud. av. vol.27, no.79, 2013. 